\title{
Defining adenoma detection rate benchmarks in average-risk male veterans
}

Mustapha M. El-Halabi ${ }^{1}$; Douglas K. Rex ${ }^{1}$; Akira Saito${ }^{1}$; George J. Eckert ${ }^{2,3}$; Charles J. $\mathrm{Kahi}^{1,4}$

1- Division of Gastroenterology and Hepatology, Department of Medicine, Indiana University School of Medicine, Indianapolis, IN, USA

2- Department of Biostatistics, Indiana University School of Medicine, Indianapolis, IN, USA

3- Richard M. Fairbanks School of Public Health, Indianapolis, IN, USA

4- Richard L. Roudebush Veterans Affairs Medical Center, Indianapolis, IN, USA

\section{Corresponding author:}

Charles J. Kahi, MD

Room C-7055, Roudebush Veterans Affairs Medical Center, Indianapolis, IN

Email: ckahi2@iu.edu

Phone: 317-944-0980

Conflict of Interest disclosure: The authors have no conflict of interest

Abstract word count: 249

Text word count: 1906 


\section{Author contributions:}

Mustapha M. El-Halabi: Conception and design; data collection; analysis and interpretation of data; drafting of the manuscript; final approval of the article Douglas K. Rex: Conception and design; critical revision of the article; final approval of the article

Akira Saito: data collection; analysis and interpretation of data; critical revision of the article; final approval of the article

George J. Eckert: Analysis and interpretation of data; critical revision of the article; final approval of the article Charles J. Kahi: Conception and design; analysis and interpretation of data; drafting of the manuscript; final approval of the article 


\section{List of acronyms:}

Veterans Affairs (VA)

Adenoma detection rate (ADR)

Indiana University (IU)

Post-colonoscopy colon cancer (PCCRC)

Institutional review board (IRB)

Computerized Patient Record System (CPRS)

First-degree relative (FDR)

Non-Steroidal Anti-inflammatory Drugs (NSAIDs)

Generalized estimating equation (GEE)

Body Mass Index (BMI)

Adenomas per colonoscopy (APC) 
Abstract:

\section{Background and Aims:}

Veterans have higher prevalence of colorectal neoplasia than non-veterans; however, it is not known whether specific Veterans Affairs (VA) adenoma detection rate (ADR) benchmarks are required. We compared ADRs of a group of endoscopists for colonoscopies performed at a VA to their ADRs at a non-VA academic medical center.

\section{Methods:}

This was a retrospective review of screening colonoscopies performed by endoscopists who practice at the Indianapolis VA and Indiana University (IU). Patients were average-risk males aged 50 years or older. ADR, proximal adenoma detection rate, advanced adenoma detection rate, and adenomas per colonoscopy were compared between IU and the VA groups.

\section{Results:}

Six endoscopists performed screening colonoscopies at both locations during the study period (470 at IU vs 608 at the VA). The overall ADR was not significantly different between IU and the VA ( $58 \%$ vs $61 \%$; $\mathrm{p}=0.21$ ). Advanced neoplasia detection rate $(13 \%$ vs $17 \%$; $p=0.46)$, proximal adenoma detection rate $(46 \%$ vs 47\%; $\mathrm{p}=0.31$ ), and adenoma per colonoscopy (1.59 vs $1.84 ; \mathrm{p}=0.24$ ) were not significantly different. There were no significant differences in cecal intubation rate (100\% vs $99 \% ; \mathrm{p}=0.13$ ) or withdrawal time (10.9 vs $11.1 \mathrm{~min} ; \mathrm{p}=0.28)$. 
In regression analysis, there was significant correlation between the attendingspecific ADRs at IU and the VA ( $p=0.041, r$-square=0.69).

\section{Conclusions:}

In this study of average-risk males undergoing screening colonoscopies by the same group of endoscopists, the ADRs of VA and non-VA colonoscopies were not significantly different. This suggests that a VA-specific ADR target is not required for endoscopists with high ADR.

Keywords: Colonoscopy, Adenoma Detection Rate, Veterans Affairs

\section{Introduction}

The adenoma detection rate (ADR), or the proportion of average-risk screening colonoscopies with at least one adenoma, is the primary colonoscopy quality indicator (1). A higher endoscopist ADR indicates a higher quality examination and has been shown to be inversely associated with the risk of postcolonoscopy colorectal cancer (PCCRC) $(2,3)$. Current ADR targets recommended by the ASGE/ACG Task Force are categorized by gender, and are $20 \%$ in females and $30 \%$ in males 50 years or older (1), reflecting the higher prevalence of colorectal neoplasia in men. There are currently no recommendations for additional ADR target adjustments based on other characteristics of the screened 
population which are known to influence adenoma prevalence, such as race/ethnicity, family history, and lifestyle factors such as smoking and obesity (4).

The Veterans Affairs (VA) system is one of the largest integrated healthcare systems in the United States, and provides care to nearly 9 million veterans a year. Most veterans are male, older, and have a higher prevalence of lifestyle risk factors (such as smoking), which might explain the higher prevalence of colorectal neoplasia compared with non-veteran populations (5-9). It is not known whether the minimum benchmark ADRs, which were developed and validated in non-veteran populations, require revision for patients who receive their care in the VA system. Although the VA has recently recognized the importance of measuring colonoscopy quality via National Directive 1015, benchmarks for ADR have not been specified, although it is generally assumed that $30 \%$ would be used by default, given that most VA patients are male (10).

The question of whether there should be a VA-specific ADR cannot be answered by comparing historical data between VA and non-VA settings, because such an approach does not take into account the operator-dependency of colonoscopy quality (11). Any comparison between the VA and other systems should compare the ADR of the same group of endoscopists working within and outside the VA. The structure of the endoscopy programs at our institution offers an opportunity to perform such a study. The Indianapolis VA is academically affiliated with, and completely integrated with the overall clinical operation at Indiana University. All GI faculty with VA responsibilities have academic appointments with the university and practice at the VA and at other non-VA IU centers. The endoscopy 
units have very similar infrastructure and resources, high commitment to quality, and use the same colonoscope models and bowel preparation options and grading.

We conducted this study to compare ADRs at the Indianapolis VA endoscopy unit to ADRs at the non-VA Indiana University (IU) endoscopy units for a group of endoscopists who practice at both locations.

\section{Methods:}

The study was approved by the institutional review board (IRB) at Indiana University and by the Research and development committee at the Roudebush Veterans Affairs Medical Center in Indianapolis, Indiana.

\section{Patient population}

This was a retrospective study which included average-risk screening colonoscopies performed between October 1, 2012 and September 30, 2015 at the Indianapolis VA medical center and at Indiana University (IU) by all gastroenterologists practicing at both institutions.

Data sources used for the study were the Veterans Affairs Vista Computerized Patient Record System (CPRS) for VA patients' information, Cerner (Cerner, Kansas City, Mo, USA) for IU patients' information, and Provation (Provation Medical Inc, Minneapolis, Minn, USA) for colonoscopy reports.

We included only colonoscopies performed on males who were $\geq 50$ years old at time of colonoscopy and for an indication of average-risk screening for colorectal cancer (no more than one first-degree relative (FDR) with CRC diagnosed at age 
older than 60 years). Colonoscopies performed on patients with FDR with CRC diagnosed at age younger than 60 years or those who had more than one FDR with CRC diagnosed at any age were excluded. Colonoscopies performed for any indication other than screening for CRC, such as postpolypectomy surveillance and diagnostic colonoscopies that included evaluation of positive fecal immunochemical tests were also excluded. "Re-screening" colonoscopies (colonoscopies performed 10 years after a negative baseline screening colonoscopy) were included in the study $(12,13)$.

\section{Data Collection}

We identified all gastroenterologists who practiced at both locations during the study time frame. Then, their eligible screening colonoscopy reports during the study period at IU and at the VA were identified. For all included patients, demographic and clinical data were collected from the colonoscopy report and the electronic medical record. Data included location (VA or IU), procedure date, time of day (AM or PM), weekend or weekday, procedure performance by attending physician alone or by a fellow under attending physician supervision, patient demographic and physical characteristics (including age, sex, ethnicity, race, weight, height), tobacco use, alcohol use, aspirin and NSAIDs use, Charlson comorbidity score, family history of colon cancer or polyps, withdrawal time (for colonoscopies where no polypectomy was performed), first time or re-screening colonoscopy status, bowel preparation quality based on the Aronchick scale, cecal intubation, and location, shape, size in millimeters, and histology of each resected polyp. 


\section{Study endpoints}

Our primary comparison was between the ADR at the VA and the ADR at IU for all gastroenterologists who performed average-risk screening colonoscopies at both locations during the study period.

Secondary comparisons between the 2 groups were performed for the advanced neoplasia detection rate, mean adenomas per colonoscopy, and serrated polyp detection rate.

Advanced neoplasms were defined as advanced adenomas $(1 \mathrm{~cm}$, villous histology, high-grade dysplasia) and cancer. Serrated polyps included hyperplastic polyps and sessile serrated polyps. Proximal location was defined as proximal to splenic flexure.

\section{Statistical Analysis}

The VA and IU groups were compared for differences in patient characteristics using 2-sample t-tests and chi-square tests for continuous and categorical variables, respectively. Generalized estimating equation (GEE) models applied to logistic regression and negative binomial regression were used to compare the groups for differences in the presence and number of adenomas, proximal adenomas, serrated polyps, proximal serrated polyps, any polyps, advanced neoplasms, and cancer, respectively. GEE models applied normally distributed data were used to compare the groups for differences in withdrawal time after a natural logarithm transformation of the withdrawal times. GEE models were used to account for clustering of patients within attending doctors. The 
following were included in the GEE models as covariates: age, body mass index (BMI), Charlson score, time of day (AM or PM), weekend, fellow participation, race (white or non-white), smoker (current/prior or not), alcohol use, aspirin or NSAID use, and rescreening . Linear regression analysis was explored for examining the association between attending-specific ADRs at IU and the VA. Analyses were performed using SAS version 9.4 (SAS Institute, Inc, Cary, NC). A 5\% significance level was used for all tests.

\section{Results:}

We identified 6 gastroenterologists who performed screening colonoscopies in average-risk patients between October 1, 2012 and September 30, 2015 at IU and the VA. A total of $470 \mathrm{IU}$ and $608 \mathrm{VA}$ colonoscopies were included in the analysis.

Patients' characteristics are presented in table 1. Patients at the VA were older, had higher Charlson comorbidity scores, and higher BMI. They were also more likely to be non-white, be smokers, use aspirin, use NSAIDs, have FDR with CRC at age older than 60 years, and their colonoscopies to be done in the afternoon, on the weekend, by a fellow under direct supervision, and have a "re-screening" indication compared with IU patients. They were less likely to drink alcohol. .

The overall ADR was not significantly different between the 2 groups (58\% at IU vs $61 \%$ at the VA; $p$-value $=0.21$ (table 2 )). In addition, detection rates of proximal adenomas, advanced neoplasms, cancers, serrated polyps or any polyps were not significantly different between the 2 groups (table 2). 
Cecal intubation rates were similar $(100 \%$ at IU vs $99 \%$ at the VA $(\mathrm{p}=0.13))$. Bowel preparation quality was graded as excellent, good, or adequate in $94 \%$ of IU colonoscopies, compared with $89 \%$ of VA ones $(\mathrm{p}=0.007)$. Withdrawal times (WT) for colonoscopies without polypectomies were not significantly different (mean WT of 10.9 minutes at IU and 11.1 minutes at the VA, p-value 0.28 (table 3)).

The number of polyps per colonoscopy was significantly higher at the VA, but the numbers of adenomas per colonoscopy (APC), proximal adenomas, serrated polyps, proximal serrated polyps, and advanced neoplasms per colonoscopy were not significantly different between IU and the VA (table 2).

Outcomes of individual endoscopists at the VA and IU are represented in table 4. Multivariable analysis comparing ADRs at IU versus VA for each of the gastroenterologists, revealed a significant correlation between the attendingspecific ADRs at IU and the VA ( $p=0.041, r$-square=0.69) (figure 1$)$.

\section{Discussion:}

This study showed that there was no significant difference between the ADR of colonoscopies performed by the same group of endoscopists in average-risk male veterans compared with average-risk male non-veterans. There was also no significant difference in advanced neoplasia detection rate or adenoma per colonoscopy detection rate between the 2 patient populations. These findings argue against setting a separate ADR benchmark for colonoscopies performed at the VA. 
To our knowledge, this is the first study that compares ADR for the same group of endoscopists in veteran and non-veteran populations. Several studies have reported ADRs at VA institutions $(5,8,9)$ and non-VA institutions $(2,3,11,14)$; however, comparisons of ADRs between the 2 settings have been limited by the inability to control for operator variability. The structure of our endoscopy programs at IU and the VA allowed us to overcome this limitation, as we were able to compare the ADRs of several endoscopists who performed colonoscopy at the VA and non-VA IU endoscopy units during the same time frame. Our study design and setting also allowed us to control other variables that could affect yield for neoplasia, including the use of the same high-definition colonoscopes and bowel preparation strategies.

Although overall ADR was not significantly different between the 2 groups, we did note that VA ADR was significantly higher for 2 endoscopists whose IU ADR was $<40 \%$. Thus it is possible that our observations depend on individual ADR, although additional study in a larger sample of endoscopists would be required to prove it.

Our study has potential limitations. First, the 2 groups were matched by endoscopist and time period; however, patients did not have similar baseline CRC risk factors. Veterans were older, had higher comorbidity burden, higher BMI, higher prevalence of smokers, but also higher prevalence of aspirin and NSAID use which would be expected to be associated with lower risk of colorectal neoplasia. Second, our study included only males. Based on previous studies from our VA that included females, we had expected $6 \%$ to $9 \%$ of our patients to be female (9). This 
small proportion was going to significantly limit our ability to compare female VA to female IU patients; hence our decision to limit the study to males. A third limitation is the relatively small number of endoscopists and colonoscopies performed during the study time period. Finally, our endoscopists had individual ADRs at the highest end of the spectrum of reported ADRs, far higher than the ACG-ASGE ADR target of $30 \%$ for males (1). This could have limited our ability to detect significant differences between VA and non-VA settings. It is not known whether our findings would differ in non-academic settings, or for endoscopists with lower ADRs.

In conclusion, this study of average-risk males undergoing screening colonoscopies by the same group of endoscopists did not show a significant difference between ADR at the VA compared with ADR at a non-VA academic center. This suggests that a VA-specific ADR target is not required. Additional study is warranted in settings where endoscopists have a wider range of ADR variability.

\section{References:}

1- Rex DK, Schoenfeld PS, Cohen J et al. Quality indicators for colonoscopy. Gastrointest Endosc. 2015;8:31-53.

2- Corley D, Jensen CD, Marks AR, et al. Adenoma detection rate and risk of colorectal cancer and death. N Engl J Med 2014;370:1298-306.

3- Kaminski MF, Regula J, Kraszewska E, et al. Quality indicators for colonoscopy and the risk of interval cancer. N Engl J Med 2010;362 : 1795803

4- Fayad NF, Kahi CJ. Quality measures for colonoscopy: a critical evaluation. Clin Gastroenterol and Hepatol 2014;12:1973-80 
5- Lieberman DA, Weiss DG, Bond JH et al. Use of colonoscopy to screen asymptomatic adults for colorectal cancer. N Engl J Med 2000;343:162-8

6- Kahi CJ, Pohl H, Myers LJ et al. Colonoscopy and Colorectal Cancer Mortality in the Veterans Affairs Health Care System: A Case-Control Study. Ann Intern Med. 2018;168:481-488.

7- Clark B, Protiva P, Nagar A et al. Quantification of adequate bowel preparation for screening or surveillance colonoscopy in Men. Gastroenterology 2016;150:396-405.

8- Rastogi A, Bansal A, Rao D et al. Higher adenoma detection rates with capassisted colonoscopy: a randomised controlled trial. Gut 2012;61:402-8

9- Kahi CJ, Ballard D, Shah A et al. Impact of a quarterly report card on colonoscopy quality measures. Gastrointest Endosc 2013;77 :925-31

10-U.S. Department of Veterans Affairs, Veterans Health Administration. Colorectal cancer screening. VHA Directive 1015. Published December 30, 2014. Accessed on June 9, 2018.

https://www.va.gov/VHApublications/ViewPublication.asp?pub_ID=3068

11-Chen SC, Rex DK. Endoscopist can be more powerful than age and male gender in predicting adenoma detection at colonoscopy. Am J Gastroenterol $2007 ; 102: 856-861$

12-Rex DK, Ponugoti PL, Johnson CS et al. Neoplasia at 10-year follow up screening colonoscopy in a private U.S. practice: comparison of a yield to first-time examinations. Gastrointest Endosc 2018;87:254-259 
13- Ponugoti PL, Rex DK. Yield of a second screening colonoscopy 10 years after an initial negative examination in average-risk individuals. Gastrointest Endosc 2017;85:221-224

14-Kahi CJ, Vemulapalli KC, Johnson C, Rex DK. Improving measurement of the adenoma detection rate and adenoma per colonoscopy quality metric: the Indiana University experience. Gastrointest Endosc 2014;79 (3):448-454.

Table 1: Patient characteristics

\begin{tabular}{|c|c|c|c|c|}
\hline & & $\mathrm{IU}(\mathrm{n}=470)$ & VA $(n=608)$ & $P$ value \\
\hline Age & & $58.07(7.62)$ & $60.25(6.62)$ & $<.001$ \\
\hline Weight (kg) & & $91.56(16.92)$ & $96.06(19.88)$ & $<.001$ \\
\hline BMI & & $28.86(5.42)$ & $30.50(6.12)$ & $<.001$ \\
\hline Charlson score & & $0.94(1.28)$ & $1.47(1.31)$ & $<.001$ \\
\hline \multirow[t]{2}{*}{ Time of day } & PM & $32(7 \%)$ & $137(23 \%)$ & $<.001$ \\
\hline & $\mathrm{AM}$ & $438(93 \%)$ & $471(77 \%)$ & \\
\hline \multirow{2}{*}{ Weekend } & Yes & $1(<1 \%)$ & $213(35 \%)$ & $<.001$ \\
\hline & No & $469(100 \%)$ & 395 (65\%) & \\
\hline \multirow[t]{2}{*}{ Fellow } & Yes & $43(9 \%)$ & $150(25 \%)$ & $<.001$ \\
\hline & No & $427(91 \%)$ & $458(75 \%)$ & \\
\hline \multirow[t]{3}{*}{ Ethnicity } & No answer & $15(3 \%)$ & $29(5 \%)$ & 0.010 \\
\hline & Hispanic & $8(2 \%)$ & $1(<1 \%)$ & \\
\hline & Not Hispanic & 447 (95\%) & $578(95 \%)$ & \\
\hline \multirow[t]{7}{*}{ Race } & No answer & $15(3 \%)$ & $28(5 \%)$ & $<.001$ \\
\hline & Other & $1(<1 \%)$ & $0(0 \%)$ & \\
\hline & islander & $2(<1 \%)$ & $1(<1 \%)$ & \\
\hline & Asian & $12(3 \%)$ & $1(<1 \%)$ & \\
\hline & $\begin{array}{l}\text { American Indian/Alaska } \\
\text { native }\end{array}$ & $2(<1 \%)$ & $2(<1 \%)$ & \\
\hline & Black/African-American & $39(8 \%)$ & $123(20 \%)$ & \\
\hline & White & $399(85 \%)$ & $453(75 \%)$ & \\
\hline \multirow[t]{4}{*}{ Smoker } & No info & $84(18 \%)$ & $121(20 \%)$ & $<.001$ \\
\hline & Previous & 55 (12\%) & $34(6 \%)$ & \\
\hline & Yes & $60(13 \%)$ & $223(37 \%)$ & \\
\hline & No & $271(58 \%)$ & $230(38 \%)$ & \\
\hline \multirow[t]{3}{*}{ Alcohol } & No info & $96(20 \%)$ & $22(4 \%)$ & $<.001$ \\
\hline & Yes & $201(43 \%)$ & $183(30 \%)$ & \\
\hline & No & $173(37 \%)$ & 403 (66\%) & \\
\hline \multirow[t]{2}{*}{ Aspirin } & Yes & $180(38 \%)$ & 301 (50\%) & $<.001$ \\
\hline & No & $290(62 \%)$ & 307 (50\%) & \\
\hline
\end{tabular}




\begin{tabular}{|llccc|}
\hline NSAIDs & Yes & $60(13 \%)$ & $109(18 \%)$ & 0.021 \\
& No & $410(87 \%)$ & $499(82 \%)$ & \\
\hline FDR cancer & Yes & $6(1 \%)$ & $21(3 \%)$ & 0.023 \\
& No & $464(99 \%)$ & $587(97 \%)$ & \\
\hline FDR polyps & Don't know & $0(0 \%)$ & $20(3 \%)$ & $<.001$ \\
& Yes & $1(<1 \%)$ & $7(1 \%)$ & \\
& No & $469(100 \%)$ & $581(96 \%)$ & \\
\hline Rescreening & Yes & $21(4 \%)$ & $58(10 \%)$ & 0.002 \\
& No & $449(96 \%)$ & $550(90 \%)$ & \\
\hline
\end{tabular}

Continuous variables (age, weight, BMI, Charlson score) are presented as Mean (SD). Categorical variables are presented as $\mathrm{n}(\%)$.

Table 2: Colonoscopy outcomes

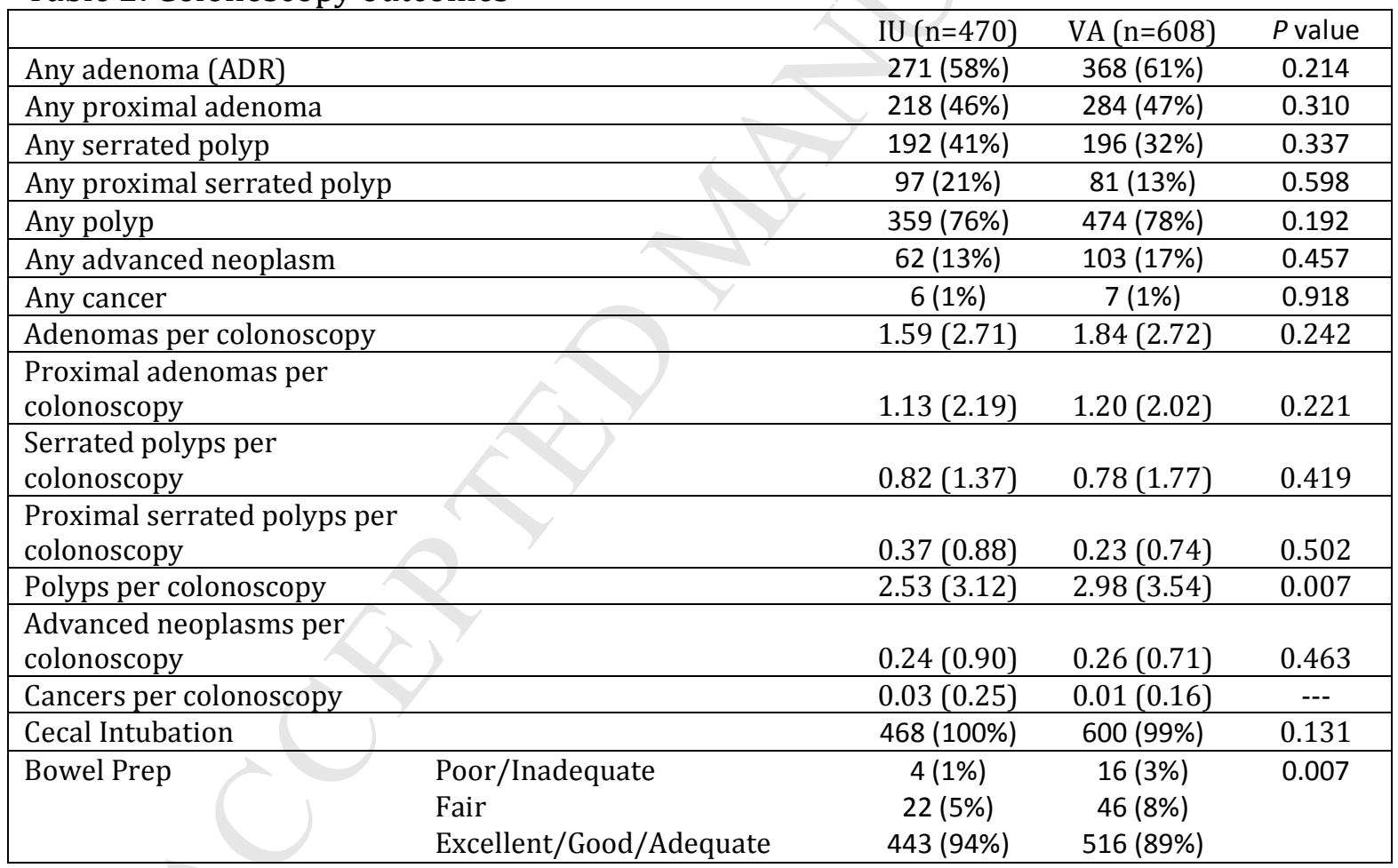

Categorical outcomes are presented as $n(\%)$. Continuous outcomes are presented as mean (SD). The p-values are adjusted for covariates described in the text.

Table 3: Withdrawal times for colonoscopies without any polyps

\begin{tabular}{|l|ll|lll|}
\hline & \multicolumn{3}{|c|}{ IU } & \multicolumn{2}{|c|}{ VA } \\
\hline Attending & N & Mean (SD) & N & Mean (SD) & $P$ value \\
\hline
\end{tabular}




\begin{tabular}{|lc|cc|ccc|}
\hline Withdrawal time (minutes) & All & 107 & $10.9(4.0)$ & 128 & $11.1(5.5)$ & 0.277 \\
\cline { 2 - 6 } & A & 13 & $11.6(2.7)$ & 41 & $15.3(6.1)$ & 0.080 \\
& B & 53 & $12.1(4.5)$ & 7 & $8.8(1.9)$ & 0.221 \\
& C & 14 & $10.0(3.5)$ & 14 & $11.6(6.2)$ & 0.256 \\
& D & 18 & $8.2(2.4)$ & 16 & $6.7(1.1)$ & 0.454 \\
& E & 2 & $11.6(1.9)$ & 18 & $7.6(1.8)$ & 0.118 \\
& F & 7 & $8.5(1.1)$ & 32 & $10.3(3.9)$ & 0.345 \\
\hline
\end{tabular}

(4 patients at IU and 6 patients at the VA did not have polyps but did not have recorded withdrawal times). Total number of patients without polyps is 111 and 134 , respectively.

Table 4: ADR, Advanced neoplasia detection rate and APC for each individual endoscopist

\begin{tabular}{|l|l|l|l|l|l|l|l|l|}
\hline \multirow{2}{*}{ Attending } & \multicolumn{2}{|l|}{ Total Procedures } & \multicolumn{2}{l}{ ADR } & \multicolumn{2}{l|}{$\begin{array}{l}\text { Advanced } \\
\text { neoplasms } \\
\text { detection rate }\end{array}$} & \multicolumn{2}{l|}{$\begin{array}{l}\text { Adenoma per } \\
\text { colonoscopy }\end{array}$} \\
\cline { 2 - 9 } & IU & VA & IU & VA & IU & VA & IU & VA \\
\hline A & 41 & 268 & $49 \%$ & $68 \%$ & $12 \%$ & $17 \%$ & $\begin{array}{l}1.34 \\
(2.20)\end{array}$ & $\begin{array}{l}1.96 \\
(2.48)\end{array}$ \\
\hline B & 274 & 46 & $62 \%$ & $65 \%$ & $14 \%$ & $18 \%$ & $\begin{array}{l}1.80 \\
(2.97)\end{array}$ & $\begin{array}{l}2.18 \\
(3.83)\end{array}$ \\
\hline C & 69 & 60 & $69 \%$ & $60 \%$ & $10 \%$ & $10 \%$ & $\begin{array}{l}1.65 \\
(1.87)\end{array}$ & $\begin{array}{l}1.45 \\
(2.08)\end{array}$ \\
\hline D & 38 & 39 & $29 \%$ & $40 \%$ & $10 \%$ & $17 \%$ & $\begin{array}{l}0.51 \\
(1.03)\end{array}$ & $\begin{array}{l}1.10 \\
(2.39)\end{array}$ \\
\hline E & 6 & 66 & $43 \%$ & $48 \%$ & $14 \%$ & $14 \%$ & $\begin{array}{l}0.43 \\
(0.53)\end{array}$ & $\begin{array}{l}1.45 \\
(2.39)\end{array}$ \\
\hline F & 19 & 118 & $37 \%$ & $57 \%$ & $16 \%$ & $20 \%$ & $\begin{array}{l}1.47 \\
(4.31)\end{array}$ & $\begin{array}{l}2.11 \\
(3.18)\end{array}$ \\
\hline
\end{tabular}

Figure 1: ADRs of individual gastroenterologists at IU and the VA showing a positive relationship ( $\mathrm{p}=0.041 ; \mathrm{r}$-square $=0.69$ ). 


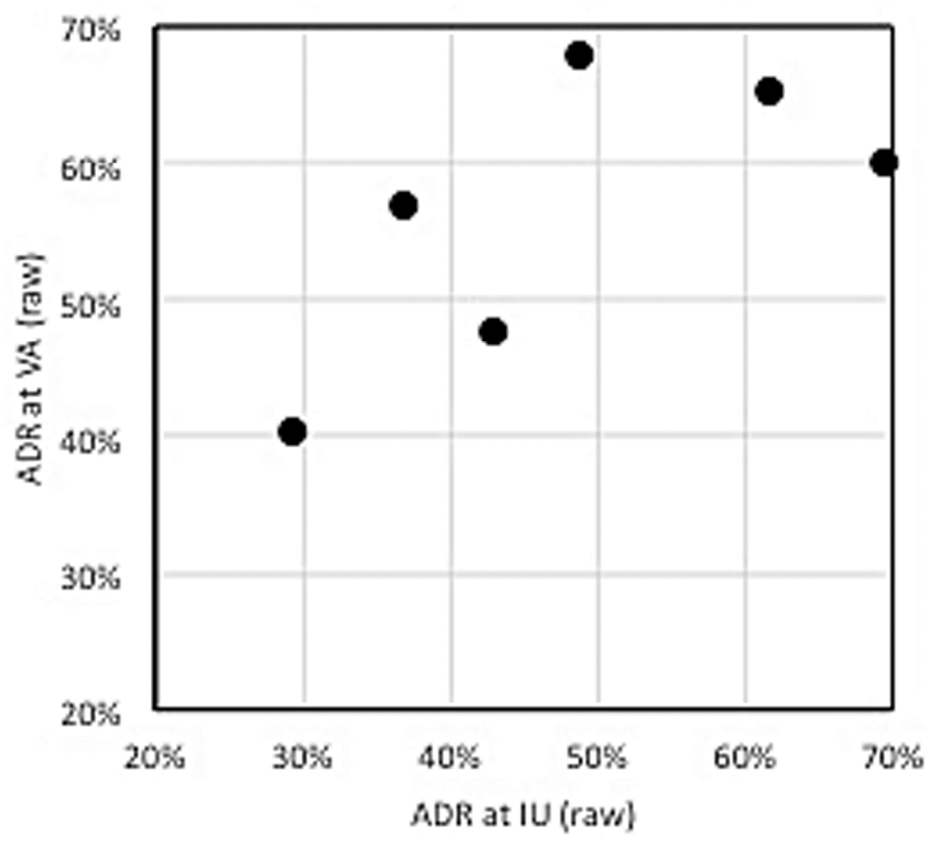




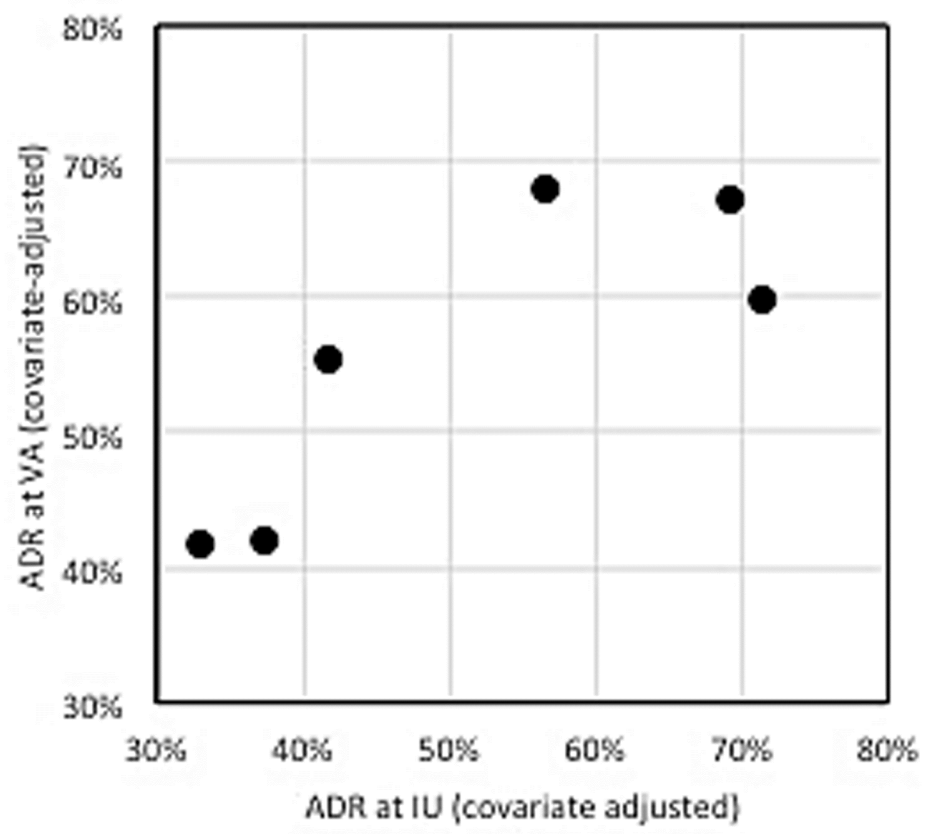

